\title{
IMPACTO AMBIENTAL E SOCIAL DAS ÁREAS VERDES NO CLIMA URBANO
}

ENVIRONMENTAL AND SOCIAL IMPACT OF GREEN AREAS IN URBAN CLIMATE

IMPACTO AMBIENTAL Y SOCIAL DE LAS ÁREAS VERDES EN EL CLIMA URBANO

\section{Douglas Gallo}

Professor Mestre, IFSP, Brasil Doutorando em Urbanismo, PROURB/FAU/UFRJ, Brasil douglas.luciano@yahoo.com.br

Léa Yamaguchi Dobbert Professora Doutora, IFSP, Brasil lea.dobbert@gmail.com

Carlos Augusto da Costa Niemeyer Professor Doutor, IFSP, Brasil carlosniemeyer@ifsp.edu.br 


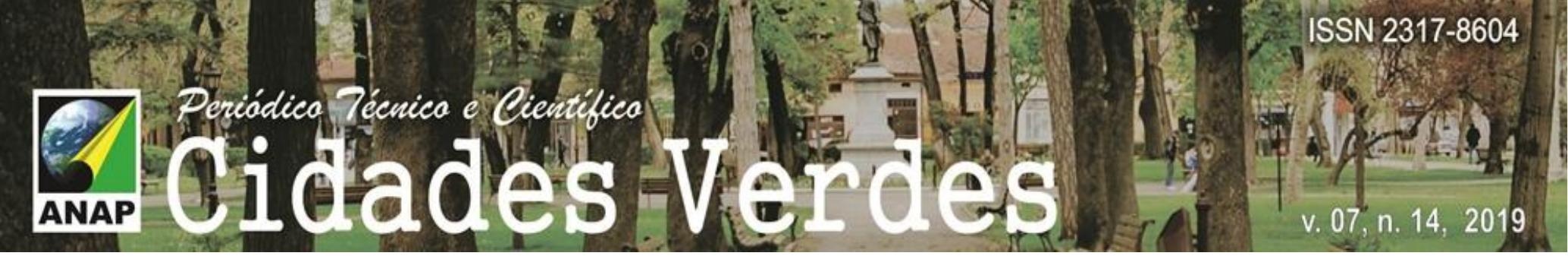

\section{RESUMO}

Este trabalho constitui a síntese de uma revisão bibliográfica do campo de estudo - conforto em espaços livres públicos - onde se busca investigar correlações existentes entre vegetação e clima urbano em várias escalas de abordagem. Neste estudo constata-se a relevância das áreas verdes na organização dos ambientes urbanos, seja pela criação de microclimas agradáveis na escala da rua e do bairro, seja na organização estética da paisagem humanizada como um direito social a preservar. Cidade, território e paisagem revelam-se partes de um patrimônio coletivo e cultural e que, por este aspecto, fundamenta a intervenção do arquiteto em sua conformação. As colocações aqui apresentadas iluminam procedimentos de desenho urbano que valorizam a importância do componente vegetal e fragmentos florestais na cidade, e a consciência de que aspectos figurativos da paisagem organizada e natural podem contribuir positivamente na apreensão cognitiva do ambiente em que vivemos.

PALAVRAS-CHAVE: Conforto ambiental urbano. Vegetação e clima urbano. Espaços livres públicos.

\section{ABSTRACT}

This work is the synthesis of a literature review of the subject "comfort in public open spaces" - which investigates correlations between vegetation and urban climate in several analysis. In this context we pointed out the relevance of green areas on urban environments by creating pleasant microclimate on the street and neighborhood scale and contributing to aesthetic organization of humanized landscape as a social right to preserve. City, territory and landscape are parts of a collective and cultural heritage, and therefore, it is justified the intervention of architect in its conformation. This study highlights some urban design procedures to value the importance of the vegetable component and forests fragments in the city, and the awareness that figurative aspects of organized and natural landscape can contribute positively in cognitive concern of the environment.

KEYWORDS: Urban thermal comfort. Urban climate and vegetation. Public spaces.

\section{RESUMEN}

Este trabajo constituye la síntesis de una revisión bibliográfica del campo de estudio - comodidad en espacios libres públicos donde se busca investigar correlaciones existentes entre vegetación y clima urbano en varias escalas de abordaje. En este estudio se constata la relevancia de las áreas verdes en la organización de los ambientes urbanos, sea por la creación de microclimas agradables en la escala de la calle y del barrio, sea en la organización estética del paisaje humanizado como un derecho social a preservar. Ciudad, territorio y paisaje se revelan partes de un patrimonio colectivo y cultural y que, por este aspecto, fundamenta la intervención del arquitecto en su conformación. Las colocaciones aquí presentadas iluminan procedimientos de diseño urbano que valoran la importancia del componente vegetal y fragmentos forestales en la ciudad y la conciencia de que aspectos figurativos del paisaje organizado y natural pueden contribuir positivamente en la aprehensión cognitiva del ambiente en que vivimos.

PALABRAS CLAVE: Confort ambiental urbano. Vegetación y clima urbano. Espacios libres públicos. 


\section{INTRODUÇÃO}

A prática do plantio de árvores em áreas urbanas surgiu no Barroco europeu com objetivo de ornamentação urbana, vindo em seu bojo alimentar a cultura citadina pelos prazeres da vida ao ar livre. De início, tímidas alamedas, implantadas nas laterais de catedrais ou passeios, traziam encantamento aos olhos dos contemporâneos, prática esta apropriada dos jardins privados da Renascença, então abertos ao domínio público (LAURIE, 1983; SEGAWA, 1985). Aos poucos foi se concebendo e consolidando tipos espaciais como o jardim público, as avenidas e alamedas arborizadas, até chegarmos aos pitorescos parques românticos servindo ora para unir centros urbanos às novas áreas de expansão, ora permitindo gerar novas práticas de convívio e sociabilidade à sombra das árvores.

Destaca-se no alvorecer do oitocentos, no contexto do salubrismo europeu irradiado a outros lugares, a consolidação da noção de saúde pública a partir do desenvolvimento da medicina social francesa tendo a cidade como palco privilegiado de grandes transformações no campo da higiene pública. É o momento em que se iniciam inúmeros programas de urbanização, trazendo soluções estéticas, tendo a arborização como destaque na construção de novas paisagens urbanas. Boulevards, bairros-jardins e até cidades-jardins foram produtos visíveis dessa nova visão de cidade, descongestionada e saudável, a apontar novos padrões civilizatórios livres dos descaminhos do industrialismo imprevidente. Interessante destacar questões emergentes aos urbanistas daquela época, conectadas à reintegração do homem à natureza, no contexto do Romantismo, momento em que os parques e demais áreas verdes passam a ser vistos como "pulmões da cidade", afirmação esta, amparada pela ciência da época (SEGAWA, 1985).

Essa tomada de posição, do então iniciante urbanismo moderno, a orientar os novos programas de "melhoramentos" urbanos que se estenderá ao longo do século XX, será o marco zero para um crescente processo de compreensão dos benefícios do componente vegetal no processo de ordenamento territorial, em que pese as idiossincrasias que permearão a conflituosa dualidade vegetação $x$ urbanização na gestão urbana (LAMAS, 2011).

\section{OBJETIVO}

O presente artigo teve como objetivo investigar as correlações existentes entre vegetação e clima urbano em várias escalas de abordagem. Pretende-se iluminar a importância do verde urbano, enquanto componente do patrimônio cultural e ambiental das cidades, ao prover melhor qualidade ambiental dos recintos urbanos.

\section{ARQUITETURA PAISAGÍSTICA E O COMPONENTE VEGETAL: algumas considerações}

Os espaços livres são importantes, às cidades sustentáveis, ao harmonizar o tráfego de pedestres permitindo maior vitalidade e habitabilidade no ambiente urbano. Dentre os muitos fatores que condicionam a qualidade ambiental urbana, o microclima exterior se faz muito importante por influenciar as possibilidades de acomodação social. Acostumados que fomos, pela visão modernista que colocava os espaços livres e vegetados como mera moldura adicional à arquitetura, quando não a uma visão pitoresca agregada ao ambiente construído, perdemos o contexto de melhor aproveitamento das virtudes do 
componente vegetal para a qualidade ambiental urbana, limitando as possibilidades de uso dos espaços livres.

A concepção bioclimática alterou conceitos arquitetônicos fortemente arraigados no planejamento racionalista. LABAKI et al (2009), destacam a inadequação de espaços arquitetônicos baseados somente em parâmetros físicos, para a qual, adicionar planejamento microclimático contribui de forma efetiva para uso mais racional dos espaços abertos ao longo de todos os dias do ano. A concepção bioclimática se fez sentir enormemente no campo do paisagismo.

Obter recintos urbanos com qualidade ambiental depende do bom agenciamento de componentes de caráter social, econômico e científico, para que provoque efeitos positivos e duradouros na cidade. Nesse contexto, e por permitir cristalizar valores sociais e culturais de longo prazo, a arquitetura paisagística é considerada também uma "arte política", quanto maior for sua área de abordagem (MAGALHÃES, 2001).

A qualidade de apropriação de um recinto dependente da sua adequação projetual a três fatores que dialogam entre si:

1. adequação funcional - em função da conformação morfológica e dimensional do recinto ao ser humano.

2. adequação estética - em função de expectativas sociais e culturais.

3. adequação ambiental - em função de exigências de conforto e salubridade para o desempenho das atividades ali previstas.

Assim, exigências de qualidade ambiental urbana evidenciam a importância do componente vegetal no agenciamento ambiental dos espaços abertos, em qualquer escala de abordagem, visando não somente prover ligações mais íntimas e funcionais entre a edificação e as áreas externas, mas, ao propiciar o controle mais racional dos rigores climáticos que afetam diretamente nossa permanência no ambiente urbano. Não por acaso, são as áreas abertas que marcam nossas lembranças de percepção de qualidade urbana, observa Lynch (1982). Influência esta, que afeta positivamente o comportamento sociopsicológico das pessoas (KAPLAN e BERMAN, 2010). Estudos científicos relatam mudanças positivas em pessoas devido ao fato de estarem em contato com a natureza, por proporcionar maior bem-estar e reduzir o estresse (MARCUS e BARNES, 1999).

Na atividade paisagística temos consciência dos elementos a serem trabalhados, como o "piso" ou plano horizontal, as "paredes" ou planos verticais e o "teto" ou plano superior. Em cada plano citado observamse distintas possibilidades de conformação do componente vegetal dentro da dimensão espaço-temporal que fundamenta o design paisagístico. O plano horizontal apresenta-se com diferentes características de permeabilidade e impermeabilidade, onde as forrações vegetais se destacam por atenuarem o desconforto de pavimentos e superfícies rígidas devido aos baixos índices de absortividade, refletância e condutividade térmica que oferecem. Estudos realizados por Monteiro et al (2008) avaliando variações térmicas de pavimentos urbanos expostos a insolação na cidade do Rio de Janeiro (Brasil) em diversas horas do dia confirmam as vantagens térmicas do piso vegetal e dos materiais de menor compacidade nos horários de pico solar (Figura 1).

O plano vertical serve a propósitos de organização de subespaços permitindo delimitar os lugares definindo ambientações e as relações escalares e ambientais desejadas. Por fim, o plano superior, ou o "teto", define níveis e padrões de proteção mais ou menos opacos. Do ponto de vista bioclimático, o teto vegetal oferece inúmeras vantagens, a começar pelo sombreamento de áreas de permanência com visível obtenção de conforto térmico obtido pela filtragem e absorção dos excessos da radiação solar incidente. 
Estudos desenvolvidos por Fatigati (2009) na cidade de São Paulo (Brasil), utilizando imagens termais do satélite LANDSAT-5 TM, revelaram acentuadas variações térmicas centro-periferia na metrópole brasileira, denominadas "ilhas de calor", chegando a diferenças da ordem de até $8^{\circ} \mathrm{C}$. Da mesma forma, Dobbert et al (2015) em estudo realizado na cidade de Campinas, utilizando-se do software EVI-met, verificaram que a variável climática temperatura do ar, foi alterada devido ao acréscimo de $20 \%$ de árvores no local de estudo, provocando a queda de $1,4^{\circ} \mathrm{C}$, corroborando a influência da cobertura arbórea na redução da temperatura do ar.

Observa-se a ocorrência de diferentes padrões de apropriação dos recintos exteriores em face do desconforto térmico promovido pela ausência pontual de arborização, confirmado por estudos efetuados por diversos pesquisadores (STEWART e OKE, 2012; OKE, 1988; GIRIDHAN et al, 2007; GULYAS et al, 2006; OLIVEIRA, et al, 2011).

Viana e Gonçalves (2001), ao analisar o desempenho do componente vegetal nos climas temperados, relatam que árvores caduciformes atenuam a quantidade de luz incidente em fachadas insoladas em cerca de $40-50 \%$. Reiterando o uso de tais tipologias vegetais em regiões de clima frio, por permitir a insolação no período de baixas temperaturas do inverno, ao mesmo tempo em que filtra os excessos no verão. Nas regiões quentes, ao contrário, espécies arbóreas de copa horizontal perenifólia, devem ser incentivadas pela proteção que oferecem às intempéries e no equilíbrio térmico ao conter a radiação incidente que seria absorvida pelas edificações. Os mesmos estudos recomendam o uso de pavimentações sombreadas e conciliadas a largas extensões de cobertura vegetal, dando preferência a materiais de baixa emissividade térmica e baixa absortividade que contribuam para mitigar a carga de energia térmica circulante na cidade (ALUCCl et al, 1986; SASHUA-BAR et al, 2010).

$\mathrm{Na}$ concepção de unidades habitacionais recomenda-se trabalhar o componente arbustivo distanciado menos de $6 \mathrm{~m}$ para portes menores que $2 \mathrm{~m}$; e mais de $6 \mathrm{~m}$ para portes maiores do que $6 \mathrm{~m}$, de forma a não interferir na circulação dos ventos em direção a aberturas localizadas em zonas de alta pressão. Os tipos arbóreos devem reiterar a solução de copa horizontal e perene em regiões quentes, ou caduciformes nas de características climáticas predominantemente frias.

\section{EFEITOS CLIMÁTICOS DOS PARQUES PÚBLICOS URBANOS}

Os parques urbanos são espaços livres públicos de dimensões significativas onde os elementos naturais predominam em sua organização física perfazendo extensas áreas permeáveis e o mínimo de impermeáveis. A concepção moderna de parque, enquanto espaço amenizador das estruturas urbanas dáse a partir da metade do século XIX no contexto do industrialismo emergente e a necessária preservação paisagístico-ambiental acrescida de exigências regressivas ligadas a expansão do lazer urbano (LAURIE, 1983).

Os parques e áreas florestais urbanas, dentro de certas condições de oferecimento, contribuem eficazmente no equilíbrio microclimático, na preservação de ecossistemas urbanos, funções psicossociais e paisagísticas ajudando ainda a organizar e fixar a legibilidade dos espaços urbanos. Atualmente, a importância dos parques urbanos adquire contornos mais abrangentes em um contexto de profundas alterações climáticas aceleradas pelo processo urbanizador. O fenômeno das "ilhas de calor", criação típica das metrópoles congestionadas do século XX, veio provocar um diferencial térmico acentuado nas áreas 


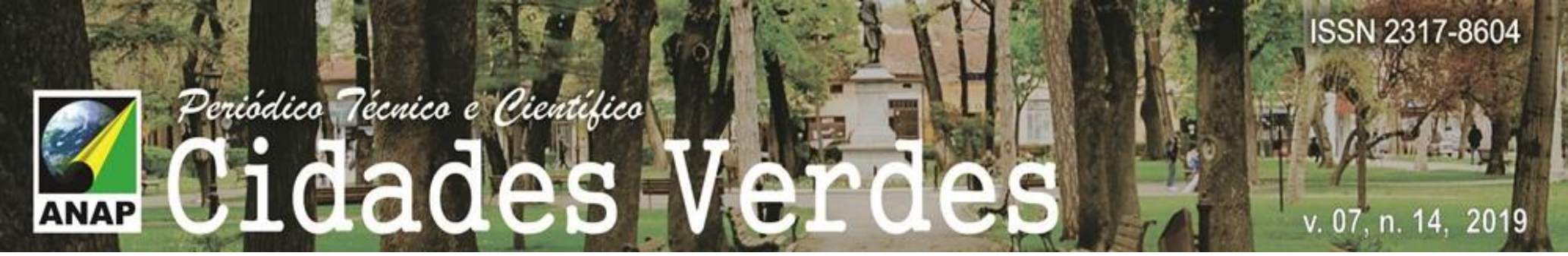

centrais em cidades de qualquer tamanho exigindo novas concepções urbanísticas mediadoras entre as necessidades do homem e do meio ambiente na formação de ambientes térmicos mais saudáveis.

Essa nova visão de desenho urbano a que chamamos "desenho ambiental" é a expressão física de um novo paradigma, chamado planejamento ambiental, que vem agregar intervenções urbanas com base no princípio da valorização e conservação das bases naturais do território, preservando e garantindo qualidade ambiental (FRANCO, 2001). O desenho ambiental propõe alterar o conceito tradicional de "espaço" urbanístico, inerte e estático, pelo de "ambiente", integrador e sustentável, onde homem e meio ambiente são parte de um mesmo processo ecossistêmico.

Conceber áreas verdes é ato fundamental de um planejamento ambiental, por propiciarem um efeito amenizador do microclima local mesmo em espaços restritos. Segundo Izard e Guyot (1983), uma faixa de vegetação entre 50 e $100 \mathrm{~m}$ de largura já produz uma notável diferença de temperatura na ordem de $3,5^{\circ} \mathrm{C}$ em bairros contíguos e um consequente aumento de $5 \%$ na umidade relativa do ar. Estudos em climatologia urbana atestam o arrefecimento térmico em áreas contíguas a bosques urbanos com benefícios climáticos, hidrológicos e biológicos, assumindo importância notável no planejamento urbano (LABAKI, 2009; GIVONI, 1998; ANJOS et al, 2012 e CARVALHO, 2001).

O clima urbano é influenciado por vários fatores, como latitude, altitude em relação ao nível do mar, topografia, proximidade de grandes extensões de água, correntes de ventos, tamanho e densidade das manchas urbanas e, significativamente, a presença de áreas verdes na forma de parques, praças ou áreas de preservação permanente (matas nativas e bosques urbanos). Sendo esses elementos essenciais ao equilíbrio térmico dos diversos setores urbanos. Contudo o tamanho de um parque faz pouca diferença nas condições climáticas dentro de seus limites e na faixa de seu efeito, segundo Givoni (1998), sendo preferivel alocar diversos pequenos parques pela zona urbana ao invês de umas poucas e extensas áreas verdes pela maior eficiência microclimática local e, é claro, pela maior acessibilidade ao lazer.

Manuais de urbanismo sugerem critérios de distanciamento entre zonas habitacionais e bosques ou florestas urbanas em função da ocorrência das chamadas sombras de vento de forma a adequá-la ao conforto térmico e as características climáticas (Figuras 2 e 3).

Figura 2: Representação esquemática de núcleo urbano em regiões quentes

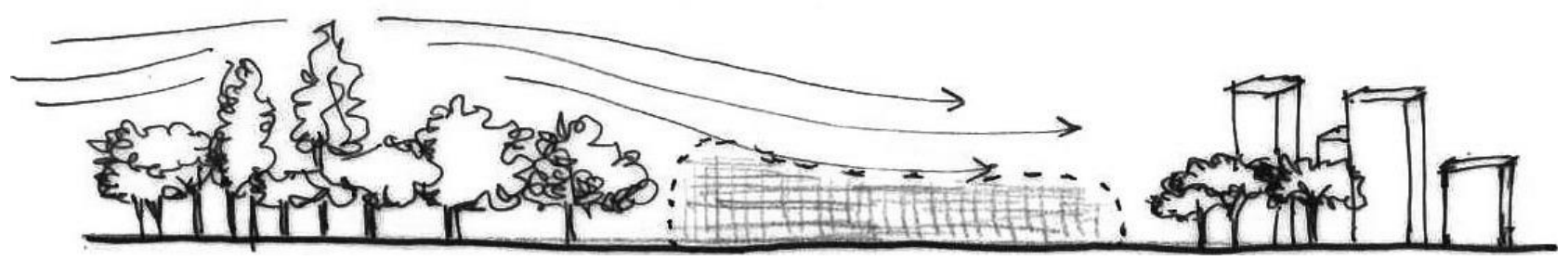

Fonte: Baseado em Alucci et al, 1986 
Figura 3: Representação esquemática de núcleo urbano em regiões quentes

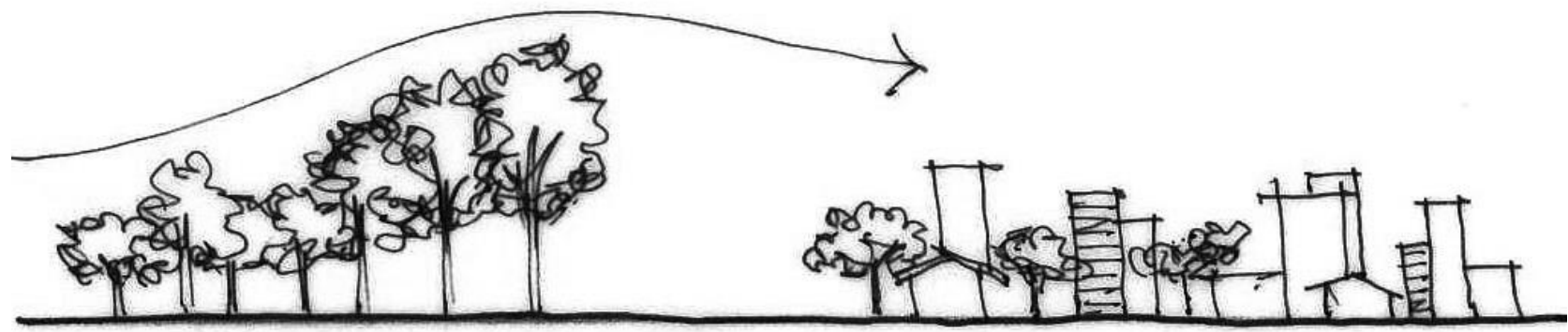

Fonte: Baseado em Alucci et al, 1986

Os Parques urbanos são extensos espaços públicos abertos, voltados primordialmente ao lazer da população, e tornam-se elementos integradores da malha urbana e referencial significativo para toda uma população. Uma rica apropriação do espaço público evidencia importante função urbana, gerada em tempos modernos: lazer e recreação como mecanismo regulador das tensões sociais (DUMAZEDIER, 1973). O Parque urbano é um elemento de composição da cidade que ajuda a fixar um senso de "comunidade" em seu entorno sem desconsiderar outros aspectos ligados à preservação do ambiente natural. Nesse aspecto, ressalta-se que o componente vegetal autóctone sugerido convenientemente no design paisagístico também reforça identidades regionais contribuindo na preservação e na construção de paisagens culturais (MAGALHÃES, 2001; LAMAS, 2011).

A referência que a população faz do parque urbano é a de uma "ilha" de amenização, isolada e fechada para a cidade, ao contrário da praça, espaço aberto. Lugar aprazível e fresco, o parque passa a percepção de um "oásis" de frescor em meio à selva de pedra, e por este aspecto integra a "rede de resfriamento" da atmosfera urbana circundante ou "park cool island" atuando na amenização do desconforto térmico das ilhas de calor (REN et al, 2013). Não se concebe a existência de uma cidade de média a grande densidade sem a presença de parques, aqui vistos na dupla função de equipamento de lazer e contraponto natural à urbanização.

A urbanística destaca a tipologia de parques e suas respectivas características formais, dimensionais e funcionais a começar pelo de menor extensão: o parque de vizinhança, o parque de bairro, o parque de setor, o parque urbano e as áreas verdes de preservação permanente. Seu tamanho pode variar desde cerca de um hectare (parques de vizinhança) a até dezenas de hectares (parques urbanos), em função de demandas específicas de atendimento. Sua característica mais evidente é a alta taxa de permeabilidade (diferentemente das praças, lugares predominantemente impermeáveis) com predomínio de elementos naturais e presença massiva do componente vegetal arbóreo em forma de bosques ou pradarias. $\mathrm{O}$ efeito psicológico que o parque proporciona é notável, podendo ser conferido na valorização imobiliária dos setores urbanos mais próximos a eles confirmando a positiva externalidade que o mesmo agrega.

Para manter seu aspecto bucólico, são estruturados essencialmente pela vegetação, definindo subespaços de permanência que organizam uso em setorizações de lazer e apropriação. Muitos parques são criados dentro ou nas bordas de Áreas de Preservação Permanente (APP), com objetivos de estimular o encontro com a natureza internalizando valores de preservação; não muito longe disso também o de consolidar uma nova cultura urbana ligada a sentimentos de solidariedade social e ambiental. 


\section{CONSIDERAÇÕES FINAIS}

A atividade humana nos espaços abertos dá-se fundamentalmente nas dimensões de qualidade dos recursos de pedestreanização: do simples footing a aspectos mais amplos de mobilidade urbana. 0 fenômeno da densificação dos centros urbanos e os impactos dela decorrentes sugerem, nesse aspecto, que nos debrucemos sobre a qualidade ambiental de nossos espaços livres, adequando-os à vida urbana enquanto palcos privilegiados da mobilidade e da interação social. Atualmente, com a crescente importância das questões ligadas à sustentabilidade social e ambiental, o foco é direcionado à aspectos do desenho ambiental aqui visto enquanto ferramenta de um design paisagístico que incorpore um conhecimento holístico abrangente focado na salubridade, no conforto e na fruição do lugar.

Vale ressaltar os pressupostos de qualificação do tecido urbano, a serem seguidos em diferentes áreas do conhecimento das ciências sociais, a orientar condições mínimas de atendimento social a que os espaços livres devem ofertar para servirem como palcos da vida urbana. Em relação à urbanística, deve-se estabelecer padrões espaciais quantitativos e qualitativos face às necessidades e demandas de inserção nas estruturas urbanas, até chegar ao planejamento paisagístico contemporâneo indicando diretrizes tecnológicas e bioclimáticas do lugar.

A busca da qualidade ambiental, seja na pequena praça de bairro até o parque urbano, distanciados dos empirismos do passado, mais do que nunca deve ser pensada dentro de uma nova realidade que modele e integre o desenho a parâmetros tecnológicos de qualidade física e sensorial entre seus vários componentes. O componente vegetal insere-se nessa perspectiva ampla de melhoria das condições do ambiente em que vivemos agora redimensionado nas lides do desenvolvimento sustentável e do conforto ambiental urbano. Seja qual for a escala de intervenção, a valorização do espaço-ambiente passa necessariamente pelo permanente processo de busca do equilíbrio ambiental e, consequentemente, a satisfação e harmonização do homem com em seu habitat.

\section{REFERÊNCIAS BLIBLIOGRÁFICAS}

ALUCCI, M.P; CARNEIRO, C.M; BARING, J. G. A. Implantação de Conjuntos Habitacionais: recomendações para adequação climática e acústica. São Paulo: IPT- INSTITUTO DE PESQUISAS TECNOLÓGICAS DO ESTADO DE SÃO PAULO, 1986.

ANJOS, M, et al, Climatologia urbana e espaços livres: contributo ao planejamento das cidades. Revista Geonorte, 2(2): 233-245, 2012.

CARVALho, M. M. Clima Urbano e Vegetação: Estudo Analítico e prospectivo do Parque das Dunas em Natal. Dissertação (Mestrado). Natal (RN), UFRN, 2001.

DOBBERT, L. D., PRATA-SHIMOMURA, A. R., MENDES, F. H., SILVA FILHO, D. F. Avaliação da interferência da cobertura arbórea no desempenho térmico por meio de simulação computacional. In: XIII Encontro Nacional e IX Encontro Latino-Americano de Conforto no Ambiente Construído, Anais... ENCAC, ENLACAC, 2015.

DUMAZEDIER, J. Lazer e Cultura Popular. São Paulo: Editora Perspectiva, 1973.

FATIGATI, F. L. Estudo da variação da temperatura da superfície do município de São Paulo no período 1991-2006 com a utilização de imagens termais do satélite LANDSAT-5 TM. In: XIV Simpósio brasileiro de sensoriamento remoto. Anais... INPE, Natal, 2009.

FRANCO, M. A. R. Desenho Ambiental. São Paulo: Annablume, 1997. 
FRANCO, M.A.R. Planejamento Ambiental. São Paulo: Annablume, 2001.

GIRIDHARAN, R et al. Urban design factors influencing heat island intensity in highrise high-density environments of Hong-Kong. Building and Environment, 42: 3669-3684, 2007.

GIVONI, B, Climate Considerations in Building and Urban Design. New York: Van Nostrand Reinhold, 1998.

GULYAS, A.; UNGER, J.; MATZARAKIS, A. Assessment of the microclimatic and human confort conditions in complex urban environment: modellings and measurements. Building and Environment 41: 1713-1722, 2006.

IZARD, J.L.; GUYOT. A. Arquitetura bioclimática. C. México: Gili, 1983.

JACOBS, J. Morte e vida de grandes cidades. São Paulo: Martins Fontes, 2001.

KAPLAN, S.; BERMAN, M.G. Directed attention as a common resource for executive functioning and self-regulation. Perspectives on Psychological Science, 5(1): 43-57, 2010.

LABAKI, L.C et al. Conforto térmico em espaços públicos abertos: aplicação de uma metodologia em cidades do interior paulista. Relatório Final de Pesquisa Fapesp. Campinas, 2009.

LAMAS, J.M.R.G. Morfologia urbana e desenho da cidade. Lisboa: Fund. C. Gulbenkian, 2011.

LAURIE, M. Introduccion a la arquitectura del paisaje. Barcelona: Ed. Gili. 1983.

LYNCH, K. A imagem da cidade. Lisboa: Ed. 70, 1982

MAGALHÃES, M.R. A Arquitectura Paisagista. Lisboa: Ed. Estampa, 2001.

MARCUS C.C.; BARNES, M. Gardens in healthcare facilities: uses, therapeutic benefits and design recommendations. Martinez: The Center for Health Design, 1999.

MONTEIRO, L. M.; GONÇALVES, J.; ALUCCI, M. P. Conforto Térmico urbano: o caso do Bairro Austin em Nova Iguaçu (RJ). NUTAU/USP - Núcleo de Pesquisa em Tecnologia da FAU/USP. $7^{0}$ Seminário Internacional - Espaço sustentável: inovações em edifícios e cidades. São Paulo, 2008.

OKE, T. Street Design and Urban Canopy Layer Climate. Energy and Buildings, 11: 103-113, 1988.

OLGYAY, V. Arquitectura Y Clima. Barcelona: Gili, 2010

OLIVEIRA, S.; ANDRADE, H.; VAZ, T. The cooling effect of green spaces as a contribuition to the mitigation of urban heat: a case study in Lisbon. Building and Environment, 46: 2186-2194, 2011.

REN, Z.; HE, X.; ZEN, H.; ZHANG, D.; YU, X.; SHEN, G.; GUO, R. Estimation of the Relationship between Urban Park Characteristics and Park Cool Island Intensity by Remote Sensing Data and Field Measurement. Forests, 4: 868-886, 2013.

RIVERO, R. Arquitetura e Clima. 2a․ Ed, Porto Alegre: DC Luzzato Editores, 1986.

SHASHUA-BAR, L.; TSIROS, I.; HOFFMAN, M. A modeling study for evaluating passive cooling scenarios in urban streets with treescase study: Athens, Greece. Elsevier, Building and Environment, 45: 2798-2807, 2010. 


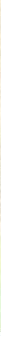

SOCIEDADE BRASILEIRA DE ARBORIZAÇÃO URBANA. Carta de Londrina (1996); Carta de Americana, 2010. Disponível em: $<w w w . s b a u . o r g . b r>$.

STEWART, I.D.; OKE, T.R. Local climate zones for urban temperature studies. American Meteorological Society. BAMS. December: 1879-1900, 2012.

VIANA, N. S.; GONÇALVES, J. C.S. Iluminação e Arquitetura. São Paulo: ed. Virtus, 2001. 